\title{
論文 Memoirs
}

\section{天空紫外線分布と大気の光學的厚さとの関係について}

\author{
關原曋*
}

\section{On a Relation between the Distribution of Ultraviolet Sky Radiation and the Optical Thickness of the Atmosphere}

\author{
Kyo Sekihara \\ Meteorological Reseurch Institute \\ Manuscript received 17 Feburary 1953)
}

\section{- Abstract -}

With the numerical calculation of the theoretical formula of primary and secondary Rayleigh scattering in a plane-stratified atmosphere of uniform composition, an influence of variation of total scattering coefficient of the atmosphere on the angular distribution of the intensity of ultraviolet sky radiation in the sun's vertical plane was discussed, when the sun's elevation angle was $30^{\circ}$ and $60^{\circ}$ respectively.

Taking the intensity at the zenith as a unit, the relative intensities from varying zenith angle were computed and were compared with the observed values of C. Dorno and F. Lindholm or 0 . Eckel which were obtained at the position of varying elevation from sea level. The theory show that the relative intensities at a comparatively large zenith angle especially at $60^{\circ}$ always increase with decreasing optical thickness of the atmosphere and these were confirmed by the observed results at both of the sun's elevation angles.

\section{1. 前置 き}

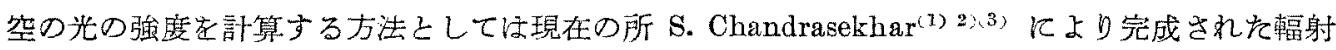

平衡の理諭が最も強力度手段を与光る名の之思われるがその数学的表現が複雑難解であるそしりは 宒れない，一方地球大気の如く比較的厚さがうすく到る所直射光が支配的である場合には高次散乱

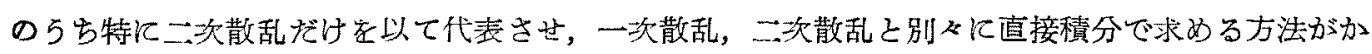
なり有効である。この方法ははじめA. Hammad 及び S. Chapman ${ }^{(4)}$ てよつて端緒が与えられ最

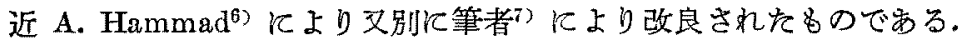

空の紫外線の角度分布の実測壮今次大戦前に主としてヨーロッパに和いて C. Dorno 及び F. Lindholm ${ }^{(8)}$ ，O. $\operatorname{Eckel}^{(9)(10)}$ 等により行なれれて居り. 興味ある実駼的事実も得られている， 天空紫外線分布の理論解析は最近オジン観測と関連してその必要老認められているもので西

* 気解矿宪所 地球化学研究宝 
る゙が，まだとれを行交つを報告をきかない，との論文は理論としては二次散乱までの不充分なる

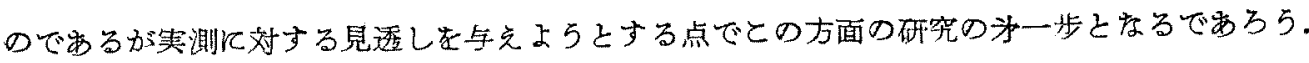

\section{2. 散乱光の理論並びに理論値の算出}

との理論については筆者が既に若干の数值計算と共に報告しているがて以下にその結果の要点を

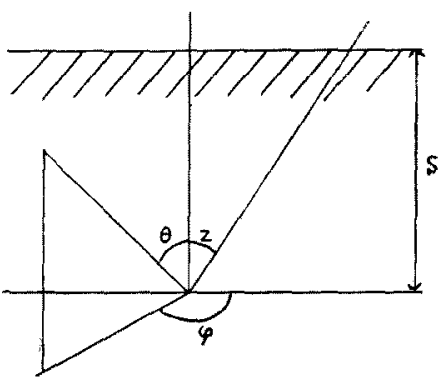

Fig. 1. Diagram of the scattering in a plane-stratified atmosphere.
のベる.

先和光学的厚さSで規定される均質疗平面大気を考劣る。 光学的厚さ $S$ と注光が垂直に透過する時の消散係数各 $S$ 或 は透過摔が $e^{-3}$ といらととである。との大気に対し垂值方向 加ら $Z$ なる傾きの方向から太陽光線が入射して来危場合，天 頂角 $\theta$ ，方位角 $\varphi$ (太陽方向加ら時計のむに上る)加らく る一次散乱光強度 $\left(R d_{1}\right)$ 及び二次散乱光强度 $\left(R d_{21}\right)$ はそれ ぞれ次式で表わされる**（Fig.1 参照)

$$
R d_{1}(z, \theta, \varphi, \delta)=\frac{3 s}{16 \pi} I_{\infty} \sec \theta\left(1+\cos ^{2} \Psi\right) e^{-s \cos \theta} \frac{e^{s(\sec \theta-\sec z)}-1}{s(\sec \theta-\sec z)}
$$

但し

$$
\cos \Psi=\cos \theta \cos z+\sin \theta \sin z \cos \phi
$$

$$
\begin{gathered}
R d_{2}(z, \theta, \varphi, 8)=\frac{9 s^{2}}{128 \pi} I_{\infty} \sec \theta\left[A_{0}(z, \theta, \varphi) L d_{1}(s, z, \theta)+A_{1}(z, \theta, \varphi) L d_{3}(s, z, \theta)\right. \\
\left.\quad+A_{2}(z, \theta, \varphi) L d_{5}(s, z, \theta)\right] \\
A_{s}(z, \theta, \varphi)=\sum_{r=0,1,2} A_{s r}(z, \theta) \cos r \varphi
\end{gathered}
$$

但し

$A_{s r}(z, \theta):$

\begin{tabular}{c|c|c|c}
\hline$r$ & 0 & 1 & 2 \\
\hline 0 & $2-\sin ^{2} \theta-\sin ^{2} z+\frac{5}{2} \sin ^{2} \theta \sin ^{2} z$ & $\frac{1}{2} \sin 2 \theta \sin 2 z$ & $\frac{1}{4} \sin ^{2} \theta \sin ^{2} z$ \\
\hline 1 & $2 \sin ^{2} \theta+2 \sin ^{2} z-6 \sin ^{2} \theta \sin ^{2} z$ & $\frac{1}{2} \sin 2 \theta \sin 2 z$ & $\frac{1}{2} \sin ^{2} \theta \sin ^{2} z$ \\
\hline 2 & $2-3 \sin ^{2} \theta-3 \sin ^{2} z+\frac{9}{2} \sin ^{2} \theta \sin ^{2} z$ & $-\sin 2 \theta \sin 2 z$ & $\frac{1}{4} \sin ^{2} \theta \sin ^{2} z$ \\
\hline
\end{tabular}

$$
L d_{n}(s, z, \theta)=e^{-s \sec \theta} \int_{0}^{1} e^{s \bar{m} \sec \theta} L_{n}(s, z, m) d \bar{m}
$$

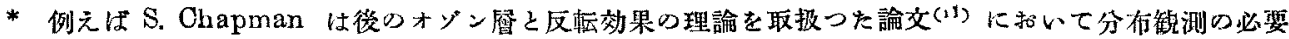

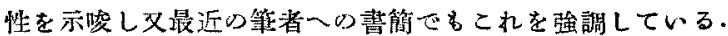

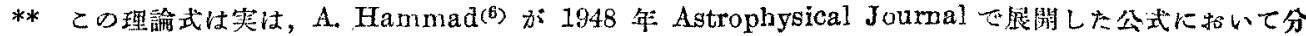

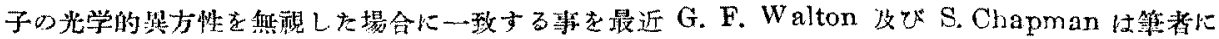
潪摘して来た。 


$$
\begin{aligned}
\operatorname{Ln}(s, z, m)=\frac{1}{s} e^{-s \bar{m} \sec z}\left(\int_{0}^{s m} e^{-t \sec z} E_{i n}(t) d t+\int_{0}^{s \bar{m}} e^{t \sec z} E_{j n}^{t}(t) d t\right) \\
(\text { 但 } \quad n=1,3,5)
\end{aligned}
$$

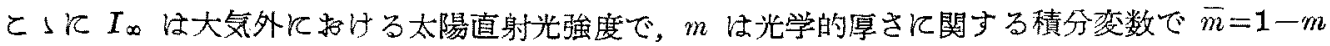

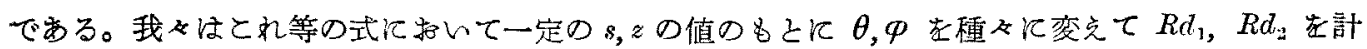

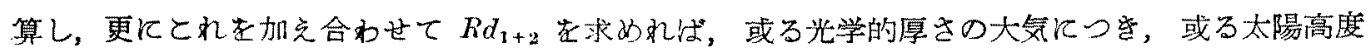

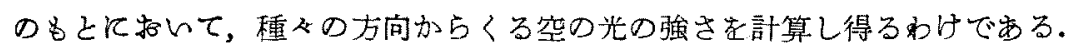

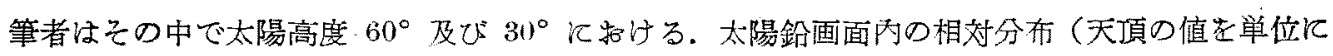

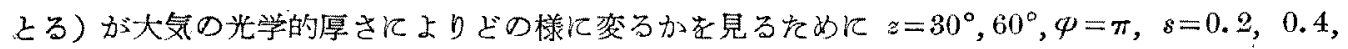

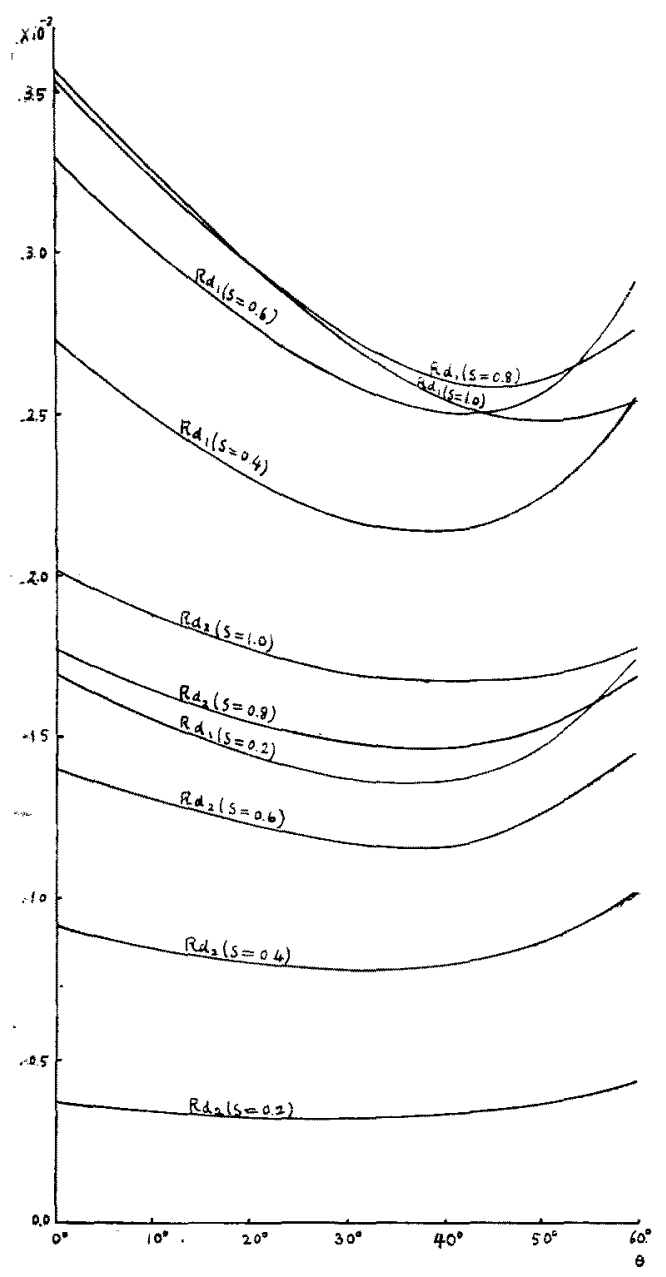

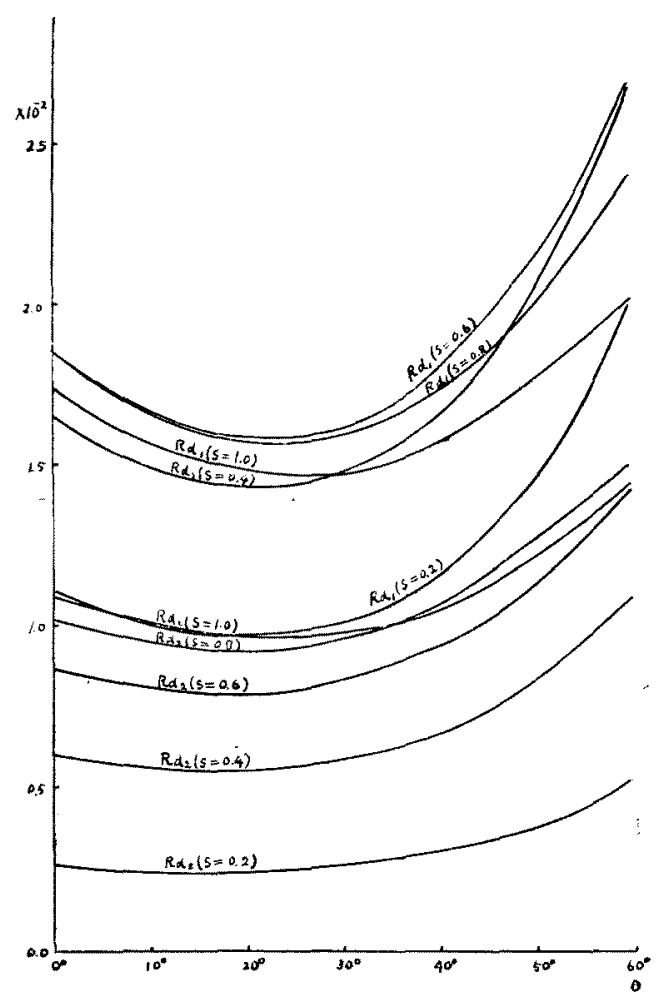

Fig. 3. Theoretical distributions of primary and secondary scattering at $z=60^{\circ}, \phi=\pi$

Fig. 2. Theoretical distributions of primary and secondory seattering at $z=30^{\circ}, p=\pi$ 


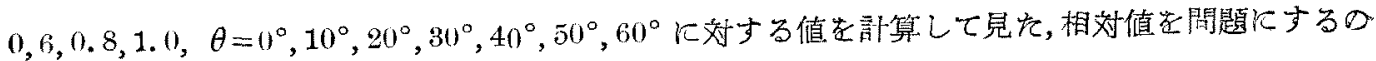
で $I_{\infty}=1$ として計算を行なつた。

計算方法は $R d_{1}$ につついては容易であり説明するまでもない，Rd，の5ち（2b）で表わされる

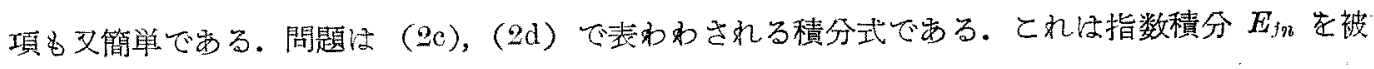

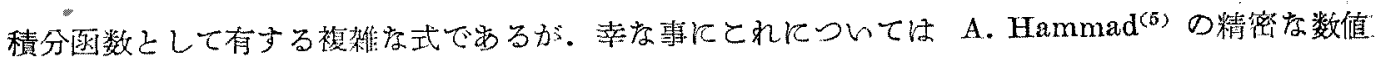
計算があり籍者はこの計算化関してはすべて彼の数值表を利用させて頃つた，但しその中で8=0.6. の所及び $z=30^{\circ}$ の值侍彼の表に次けているのであるがてれは圖式内捙法で求めた.

計算絬果洁 Tab. Ia，Ib，IIa，IIb の通りである.とのグラフを Fig. 2，Fig. 3 と示す。これ

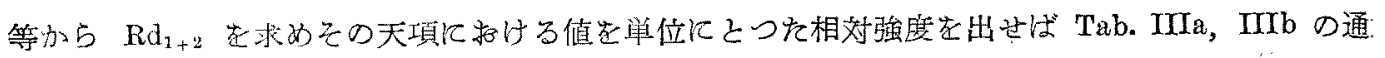

Tab. Ia Calculated intensities of primary scattering at $z=30^{\circ}$

\begin{tabular}{|c|c|c|c|c|c|c|c|}
\hline , & $0^{\circ}$ & $10^{\circ}$ & $20^{\circ}$ & $30^{\circ}$ & $40^{\circ}$ & $50^{\circ}$ & $60^{\circ}$ \\
\hline 0.2 & 0.0164 & 0.0155 & 0.0144 & 0.0137 & 0.0136 & 0.0146 & 0.0174 \\
\hline 0.4 & 0.0272 & 0.0249 & 0.0230 & 0.0217 & 0.0213 & 0.0223 & 0.0255 \\
\hline 0.8 & 0.0328 & 0.0301 & 0.0277 & 0.0259 & 0.0250 & 0.0255 & 0.0281 \\
\hline 0.8 & 0.0353 & 0.0323 & 0.0296 & 0.0274 & 0.0260 & 0.0260 & 0.0276 \\
\hline 1.0 & $0.035 t$ & 0.0325 & 0.0296 & 0.0272 & 0.0254 & 0.0248 & 0.0254 \\
\hline
\end{tabular}

Tab. Ib Calculated intensities of secondary scattering at $z=30^{\circ}$

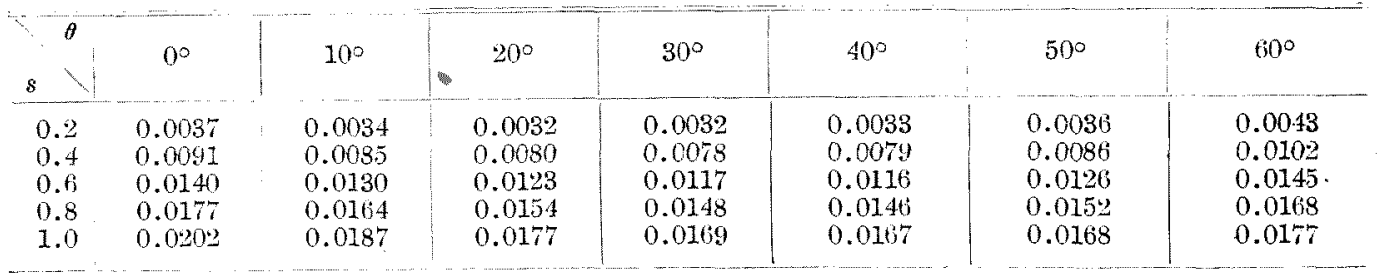

Tab. Ila Calculated intensities of primary scattering at $z=60^{\circ}$

\begin{tabular}{c|c|c|c|c|c|c|c}
\hline${ }^{\theta}$ & 0 & & & & & & \\
$s$ & & $10^{\circ}$ & $20^{\circ}$ & $30^{\circ}$ & $40^{\circ}$ & $50^{\circ}$ & $60^{\circ}$ \\
\hline 0.2 & 0.0111 & 0.0100 & 0.0097 & 0.0101 & 0.0115 & 0.0145 & 0.0200 \\
0.4 & 0.0165 & 0.0149 & 0.0143 & 0.0147 & 0.0166 & 0.0204 & 0.0268 \\
0.6 & 0.0185 & 0.0167 & 0.0159 & 0.0162 & 0.0180 & 0.0215 & 0.0270 \\
0.8 & 0.0185 & 0.0166 & 0.0157 & 0.0159 & 0.0173 & 0.0200 & 0.0241 \\
1.0 & 0.0174 & 0.0156 & 0.0149 & 0.0147 & 0.0157 & 0.0177 & 0.0202 \\
\hline
\end{tabular}

Tab. IIb Calculated intensities of secondary scattering at $z=60^{\circ}$

\begin{tabular}{c|c|c|c|c|c|c|c}
\hline \multicolumn{1}{c}{$\theta$} & $0^{\circ}$ & $10^{\circ}$ & $20^{\circ}$ & $30^{\circ}$ & $40^{\circ}$ & $50^{\circ}$ & $60^{\circ}$ \\
\hline$s$ & & & & & & & \\
\hline 0.2 & 0.0026 & 0.0024 & 0.0024 & 0.0026 & 0.0030 & 0.0038 & 0.0053 \\
0.4 & 0.0060 & 0.0056 & .0 .0055 & 0.0059 & 0.0067 & 0.0083 & 0.0109 \\
0.6 & 0.0087 & 0.0081 & 0.0079 & 0.0084 & 0.0094 & 0.0113 & 0.0149 \\
0.8 & 0.0102 & 0.0095 & 0.0092 & 0.0096 & 0.0106 & 0.0127 & 0.0150 \\
1.0 & 0.0109 & 0.0101 & 0.0097 & 0.0098 & 0.0105 & 0.0121 & 0.0144 \\
\hline
\end{tabular}


Tab. IIIa Relalive intensities of primary and secondary scattering at $z=30^{\circ}$

\begin{tabular}{c|c|c|c|c|c|c|c|c}
\hline & 0 & $10^{\circ}$ & $20^{\circ}$ & $30^{\circ}$ & $40^{\circ}$ & $50^{\circ}$ & $60^{\circ}$ \\
\hline 0.2 & 1.00 & 0.92 & 0.86 & 0.82 & 0.82 & 0.88 & 1.07 \\
0.4 & 1.00 & 0.92 & 0.86 & 0.81 & 0.81 & 0.85 & 0.98 \\
0.6 & 1.00 & 0.92 & 0.85 & 0.80 & 0.78 & 0.81 & 0.91 \\
0.8 & 1.00 & 0.92 & 0.85 & 0.79 & 0077 & 0.78 & 0.84 \\
1.0 & 1.00 & 0.92 & 0.85 & 0.79 & 0076 & 0.75 & 0.77 \\
\hline
\end{tabular}

Tab. IIIb Relative intensities of primary and secondary scattering at $z=60^{\circ}$

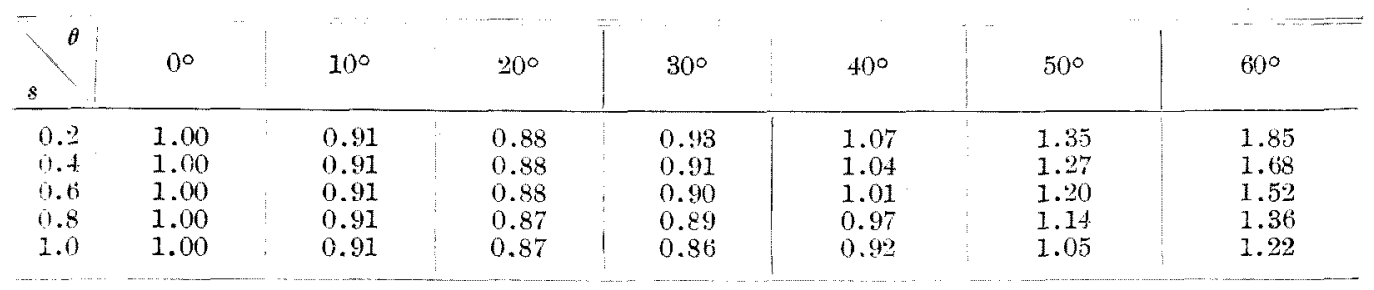

Tab. IVa Observed relative intensities of ultraviolet sky radiation in the vertical plane through the sun and in its opposite side at $z=30^{\circ}$

\begin{tabular}{|c|c|c|c|c|c|c|c|c|}
\hline \multirow{2}{*}{$\begin{array}{l}\text { Place of Observation } \\
\text { (Elevation) }\end{array}$} & \multicolumn{7}{|c|}{ Zenith angle } & \multirow{2}{*}{ Author } \\
\hline & $0^{\circ}$ & $10^{\circ}$ & $20^{\circ}$ & $30^{\circ}$ & $40^{\circ}$ & $50^{\circ}$ & $60^{\circ}$ & \\
\hline Gmunden $(430 \mathrm{~m})$ & 1.00 & 0.86 & 0.76 & 0.70 & 0.66 & 0.64 & 0.64 & O. Eckel (10) \\
\hline (Föhn-weather) & 1.00 & 0.90 & 0.83 & 0.78 & 0.75 & 0.74 & 0.80 & O. Eckel (10) \\
\hline $\begin{array}{l}\text { Kanzelhöhe in } \\
\text { Kärnten }(1500 \mathrm{~m})\end{array}$ & 1.00 & 0.88 & 0.80 & 0.76 & 0.74 & 0.75 & $0 . \dot{80}$ & O. Eekel (9) \\
\hline Davos $(1600 \mathrm{~m})$ & 1.00 & 0.87 & 0.83 & 0.75 & 0.75 & 0.76 & 0.81 & C. Dorno (8) \\
\hline
\end{tabular}

Tab. IVb Observed relative intensities of ultraviolet sky radiation in the vertical plane through the sun and in its Opposite Side at $z=60^{\circ}$

\begin{tabular}{|c|c|c|c|c|c|c|c|c|}
\hline \multirow{2}{*}{$\begin{array}{l}\text { Place of Ohservation } \\
\text { (Elevation) }\end{array}$} & \multicolumn{7}{|c|}{ Zenith angle } & \multirow{2}{*}{ Author } \\
\hline & $0^{\circ}$ & $10^{\circ}$ & $20^{\circ}$ & $30^{\circ}$ & $40^{\circ}$ & $50^{\circ}$ & $60^{\circ}$ & \\
\hline $\begin{array}{c}\text { Friedlichshafen } \\
(4.00 \mathrm{~m})\end{array}$ & 1.00 & $0.96^{\circ}$ & 0.93 & 0.94 & 0.95 & 1.08 & $(1.20)$ & C. Dorno (8) \\
\hline Gmunden $(430 \mathrm{~m})$ & 1.00 & 0.94 & 0.92 & 0.94 & 0.99 & 1.10 & 1.22 & O. Eckel (10) \\
\hline $\begin{array}{l}\text { Kanzelhölue in } \\
\text { Kärnten }(1500 \mathrm{~m})\end{array}$ & 1.00 & 0.94 & 0.93 & 0.95 & 1.01 & 1.14 & 1.28 & O. Eckel (9) \\
\hline Davos $(1600 \mathrm{~m})$ & 1.00 & 0.97 & 0.92 & 0.89 & 1.00 & 1.11 & 1.23 & C. Dorno (8) \\
\hline$\underset{(2450 \mathrm{~m})}{\text { Muottas muraigl }}$ & 1.00 & 1.00 & 0.98 & 1.14 & 1.36 & 1.57 & 1.98 & C. Dorno (8) \\
\hline Sonblick $(3100 m)$ & 1.00 & 0.95 & 0.93 & 0.96 & 1.04 & 1.17 & 1.35 & O. Eckel (10) \\
\hline
\end{tabular}


りとなる，その $\theta$ による変化或は 8 による変化の模様を圆示すれば Fig. $4 \mathrm{a}, 4 \mathrm{~b}, 5 \mathrm{a}, 5 \mathrm{~b}$ となる。

\section{3. 計算結果の考察並びに実測值との対比}

Fig. 2 及び Fig. 3 は太陽天項角 $30^{\circ}$ 及び $60^{\circ}$ に扣ける一次並びに二次散乱の强度分布殊にそ

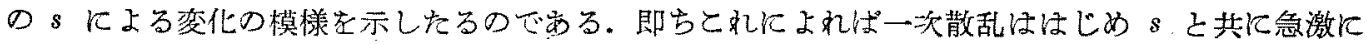

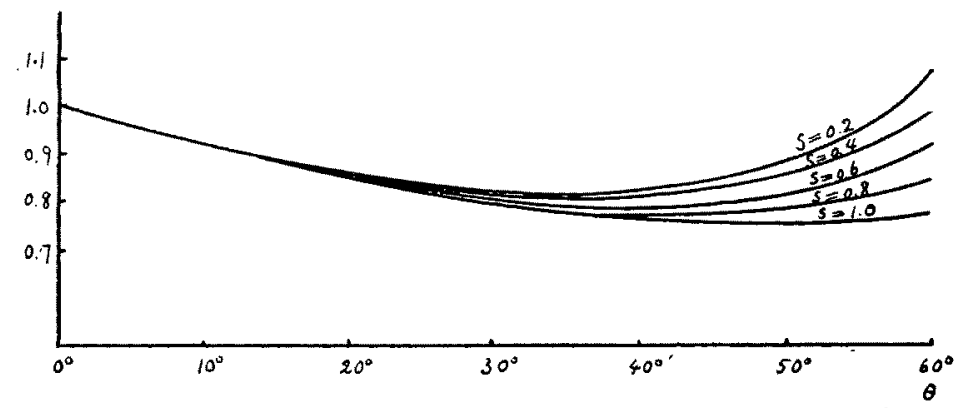

Fig. 4. Theoretical relative distributions of scattered light at $z=30^{\circ}, \varphi \doteq \pi$ (a) Variation with $\theta$

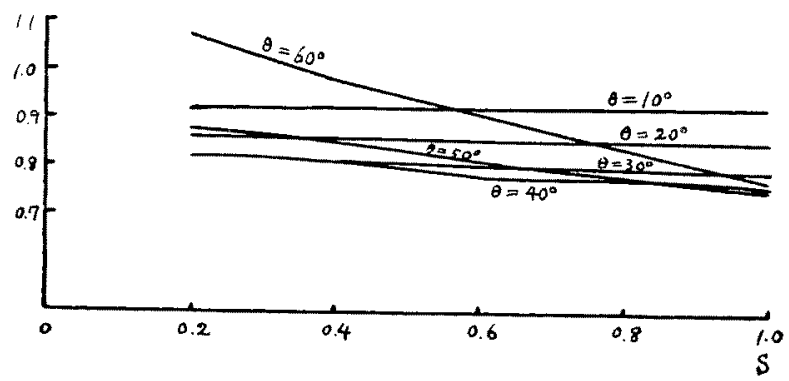

(b) Variation with $s$

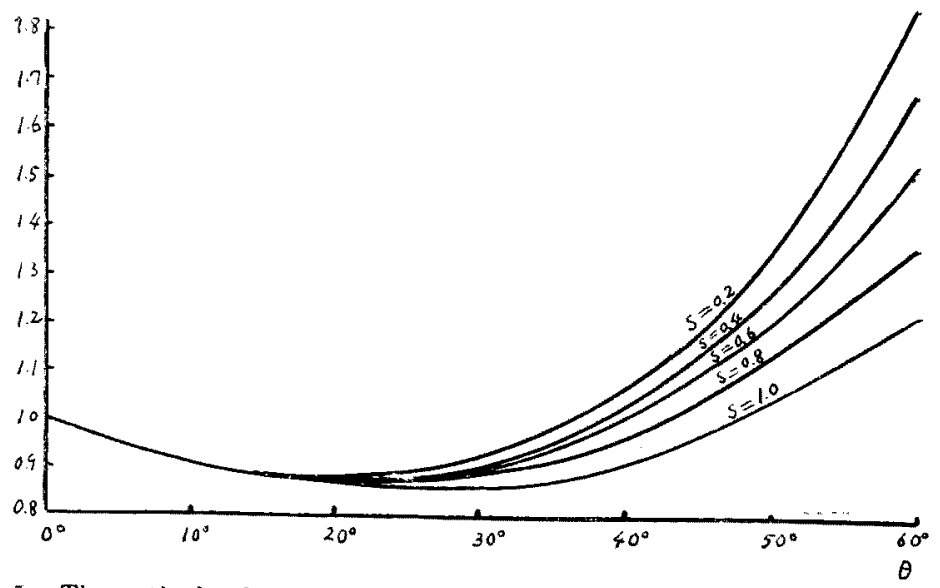

Fig. 5. Theoretical relative distributions of scatterd light at $z=60^{\circ} . \phi=\pi$

(a) Variation with $\theta$ 


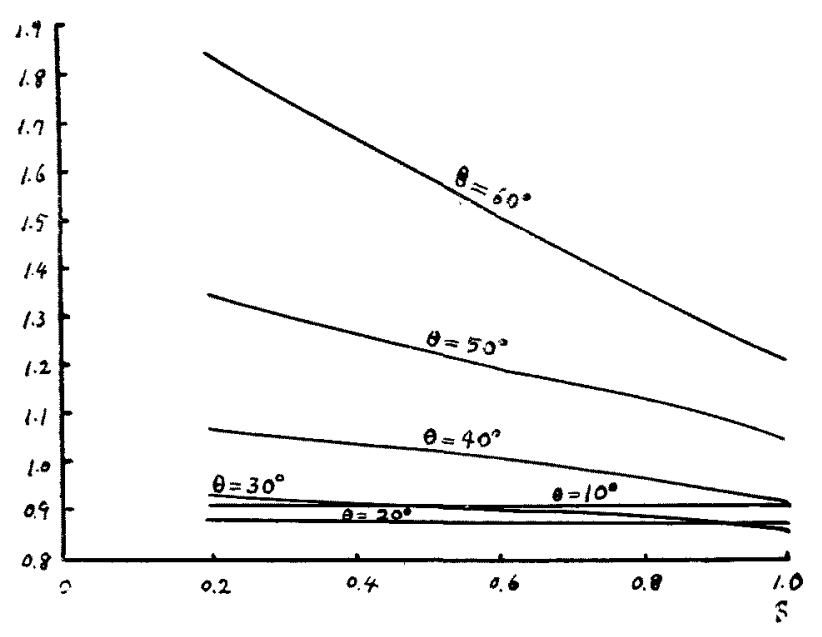

Fig. 5 (b) Variation with $s$

增大し， $s=1$ の附近で極大に達し終 には減少の傾向をとり，二次散乱は これに反し最後まであまり大きな変 動なしに增大している。とれにより $s$ の大き店所では二次散乱の役割が 重要となつてくる事が分る。いすれ にしても天頂角の大きな方向に和け る値は天頂の值に比し $s$ 増大と共 に小さくなる傾向にあり，その事は 天頂角の大きい程著しん。これは最 後の $R d_{1+2}$ の相対值に最も明らかに 表わされて居り Tab.IIIa, IIIb 或は

Fig. $4 a ， 4 b ， 5 a ， 5 b$ 等衣見れば容易に観察し得る. 更に Fig. $4 b ， 4 b$ によればその㕠化が非常に. 直線的に近い事々興味深い事でめる5.

ともかくもとなで大氮の光学的厚さが減少すると天項角の大き方方からくる光の強さの天頂の 值に対する測対值が大をくなるという結論が得られたが実はとれは０. Eckel に上り実测的にたし

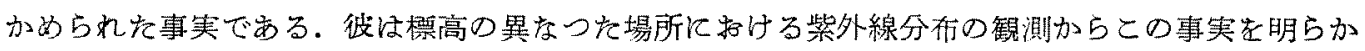
に指摘している10 これを見るために，C. Dorno, F. Lindhohn, O. Eckel 等の観測結果孝観地点 の標高龙附して再び Tab. IVa, IVb にかいげる。云うまでもなく整高が上れぱとれに従い大気の

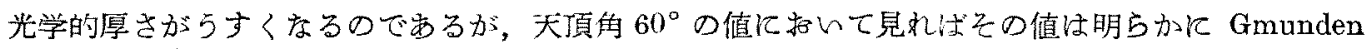
$(430 \mathrm{~m}) \rightarrow$ Kanzelgöhe in Kärnten $(1500 \mathrm{~m}),\left(z=30^{\circ}\right)$ 或は Gmunden $(430 \mathrm{~m}) \rightarrow$ Kanzelhöhe in Kärnten $(1500 \mathrm{~m}) \rightarrow$ Sonnblick $(3104 \mathrm{~m})\left(z=60^{\circ}\right)$ 或は Friedlichshafen $(400 \mathrm{~m}) \rightarrow$ Davos $(1600 \mathrm{~m})$

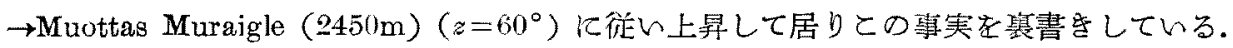

但しこの場合の定量論在考えるのにこの波長の紫外線に對しては(いずれも测定はカドミウム光 電管で波長柱 $3200 \AA$ 附近之考充られる) 大氮の光学的厚さ海面上で $s=0.86,400 \mathrm{~m}$ で 0.81 , $1600 \mathrm{~m}$ で $0.70,2450 \mathrm{~m}$ で 0.62 の程度と考党られるが，Tab. IIIa，IIIb 或は Fig. 4a,4b, 5a, 5b ¿ Tab. IVa，IVb と在比較すれば分る様に概して実测より理論值の方が天頂角の大きい所で大き

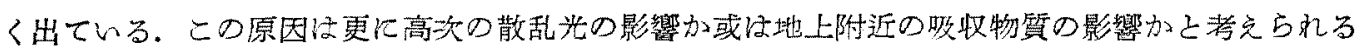

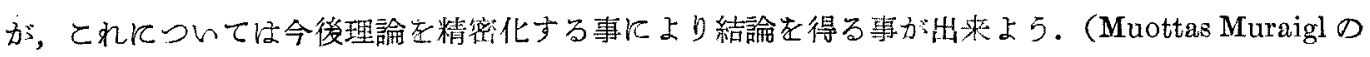
值は例外的に大をいがこれについては後に述べる).

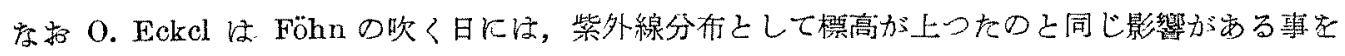


指摘している(10) (Tab. IVaの Gmunden の normal 及び Föhn の項参照). との原因注大纹 の物理的状態の変化にあると考えられるが，考文得る要因としては大気上層のオジン層の変動々地

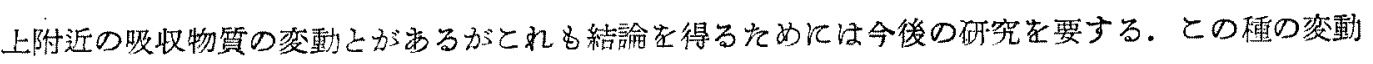
と見做されるものは筷は Tab. IVb Kも見られる. 即ち C. Dorno, F. Iindholm の Muottas Muraigl (2450m) の天頂角 $60^{\circ}$ の值は. O. Eckel の Sonnblick (3100m)の值より著しく大き い.とれも同種の大気の物理的状態の変化㳖わしていると見てよいであるら.

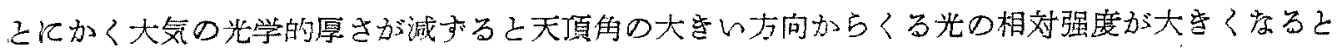

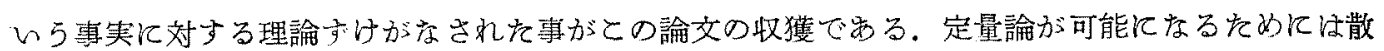

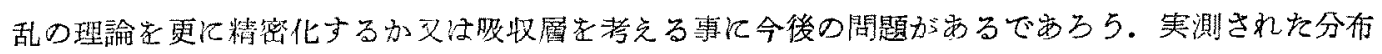

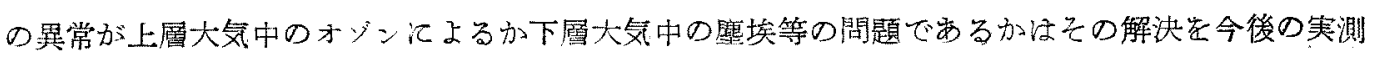
几走つ所が大きいであるら。

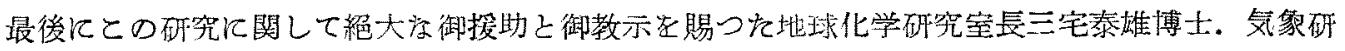

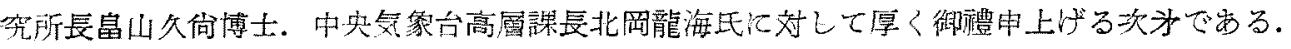

\section{参考交献}

(1) S. Chandrasekhar, 1944-1949: On the Radiative Equilibrium of a Steller Atmosphere (I-XXIV). Asirophysical Journal. 100 109

(2) S. Chandrasekhar, 1950: Radiative Transfer, Oxford.

(3) S. Chandrasekhar, 1951.: Polarization of the Sunlit Sky Nature 167, No. 4237. p. 51 55.

(4) A. Hammad, and S. Chapman, 1939.: The Primary and Secondary Seattering of Sunlight in a Plane-stratified Atmosphere of Uniform Composition, Philosophical Magazine Ser. 7.28 p. 99.

(5) A. Hammad. 1947: Philosophical Magazine Ser. 7. 38, p. 527.

(6) A. Hammad, 1948: Astrophysical Journal 108, p. 338.

(7) K. Sekihara, 1951.: Studies of the Distribution of Ultraviolet Sky Radiation (II) - On the Role of Secondary Scattering Papers in Meteorology and Geophysics 11. No. 2. p.

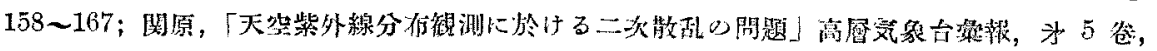
为1等, 65 开 75 真. (昭和 26 年 3 月).

(8) C. Dorno, and F. Lindholm, 1929.: Helligkeit Verteilung über der Himmel im Ultraviolet, Meteorologische Zeitschrift Bd. 46, S. 281 292.

(9) O. Eckel, 1934.: Die Verteilung der Ultravioletstrablung über das Himmelsgewölbe, Meteorologische Zeitsehrift Bd. 51. S. 180 188*

(i0) O. Eckel, 1936.: C̈ber einige Eigenschaften der ultravioletten Himmelstrahlung im verschiedenen Meershöhen und bei Föhnlage, Meteorologische Zeitschrift, Bd. 71. S. 90 94.

(11) S. Chapman, 1935.: The Götz Inversion of Intensity-Ratio in Zenith-Scattered Sunlight, Philosophical Transactions of the Royal Society of London, Series A. 234, p. 205. 